\title{
Phenotypic Characterization of Salmonella Typhimurium Isolates from Food-animals and Abattoir Drains in Buea, Cameroon
}

\author{
Jane-Francis T.K.Akoachere', Nicoline F.Tanih',2, Lucy M. Ndip', and Roland N. Ndip ${ }^{1,2}$ \\ 'Department of Biochemistry and Microbiology, Faculty of Science, University of Buea, PO Box 63, Buea, Cameroon and \\ ${ }^{2}$ Department of Biochemistry and Microbiology, Faculty of Science and Agriculture, University of Fort Hare, \\ P/Bag XI3 4, Alice 5700, South Africa
}

\begin{abstract}
Salmonella spp. have been extensively incriminated worldwide as common causes of bacterial gastroenteritis in humans, with food-animals serving as important reservoirs. The study was aimed at investigating cattle and pigs slaughtered in Buea as reservoirs of Salmonella Typhimurium and the susceptibility of isolates to antibiotics. In total, 230 specimens (comprising 50 each from the rectum, ileum, and gall bladder of cattle; and 10 each from same anatomical sites of pigs and 50 from abattoir drains) were analyzed for Salmonella using the standard microbiological, biochemical and serological techniques. Antibiotic susceptibility of the isolates was determined by the Kirby-Bauer disc-diffusion test. The isolates were characterized into biotypes using the API 20E kit, and results were analyzed using the chi-square test. Seventy-five (32.6\%) of the 230 specimens were positive for $S$. Typhimurium, with pigs and abattoir drains presenting the highest level of isolation (40\%). Biochemical typing grouped the isolates into five biotypes. Biotype I was the most prevalent (30.6\%) while biotype IV was the least prevalent (9.3\%) and was absent in samples from pigs. Antibiotic susceptibility studies revealed 14 antibiotypes based on antibiotics used in the study. The predominant antibiotype $\mathrm{AMX}^{\mathrm{R}} \mathrm{DOX}^{\mathrm{R}} \mathrm{CEF}^{\mathrm{R}}$ was recorded in 13 (17.3\%) of the isolates. Multidrug resistance (to four or more antibiotics) was recorded in 50.7\% (38/75) of the isolates. The most active drugs were ciprofloxacin (98.6\%), ofloxacin (93.3\%), amikacin (90.6\%), and gentamicin (84\%). All the isolates (100\%) were resistant to tetracycline and ampicillin. Cattle and pigs were found to be reservoirs of $S$. Typhimurium in the environment of Buea, Cameroon, implying that foods from these sources, if not properly handled, could serve as vehicles for its transmission to humans.
\end{abstract}

Key words:Antibiogram; Antibiotic resistance; Biotyping; Drug resistance, Microbial; Gastroenteritis; Salmonella infections; Salmonella Typhimurium; Cameroon

\section{INTRODUCTION}

Salmonella enterica, a Gram-negative, non-sporing, catalase-positive, oxidase-negative facultative anaerobic bacilli is a significant cause of morbidity and mortality in humans and animals, with multidrugresistant $S$. enterica serovar Typhimurium being an emerging problem (1-4). Contaminated food of animal origin, particularly meat products from cattle

Correspondence and reprint requests should be addressed to:

Dr. Roland N. Ndip

Department of Biochemistry and Microbiology

University of Fort Hare

P/Bag X1314, Alice 5700

South Africa

Email: rndip@ufh.ac.za

Fax: (+27) 866224759 and pigs, is an important source of $S$. Typhimurium in human infections (5). S. Typhimurium has been described as a collection of variants that vary significantly in their host range and their degree of host adaptation (6). It is the third most common serovar causing human food-poisoning in some parts of the world. As pathogens, they have developed complex virulence mechanisms to evade host defence mechanisms (7). Although the organism does not cause clinical disease in pigs, subclinical infections constitute an important foodsafety problem throughout the world (8), and from a consumer viewpoint, continuing efforts are needed to reduce its occurrence in pork.

$S$. Typhimurium can survive in the environment, and once established on a farm, contamination can be difficult to eradicate. It may spread from farm to 
farm through exchange of livestock, by wildlife, or in the runoff from fields and can disseminate into food-chains as a consequence of further cross-contamination at slaughter-houses. Due to the ability of Salmonellae to survive in meat and animal products that are not thoroughly cooked or not properly handled, animal products are the main vehicles of salmonellosis (4).

Typing of $S$. Typhimurium provides information on strain diversity and improves the epidemiological analysis of outbreaks $(9,10)$. Several methods, including biotyping, profiling of antibiotic susceptibility, phage-typing (11), pulsed-field gel electrophoresis (PFGE) (12), plasmid profile analysis (13), and various PCR-based techniques have been used for characterizing the organism. However, although phage-typing, PFGE, and PCR-based techniques have a high discriminatory power, they are more complex, cumbersome, and expensive, making these not suitable for routine investigation or for laboratories with limited resources as is common in developing countries. Zhou et al. employed biotyping as an effective means to the investigation and surveillance of $S$. Typhimurium-associated nosocomial infection (14); their findings demonstrated a link between infection in children and bacteria in hospital environments and carriers of medical staff. In the present study, we employed biotyping and antibiogram previously reported in our laboratory (15) as they offer advantages to smaller laboratories, such as ours, which are not optimally equipped.

The emergence of multidrug-resistant (MDR) serotypes, especially $S$. Typhimurium definitive phagetype (DT) 104, has become a potential problem for animal husbandry and in human medicine (16-19). Animals infected with antibiotic-resistant Salmonella are an important source of resistance determinants that can transfer to human-infective Salmonella serovars.

Considerable information abounds on distribution of serotypes and antimicrobial susceptibility of Salmonella of human and of food-animal origin in other parts of the world $(8,20)$. However, a dearth of information exists on non-typhoidal Salmonella in most parts of Cameroon, including Buea (21). This study was, therefore, carried out to determine the role major food-animals (cattle and pigs) play as reservoirs of $S$. Typhimurium and also to study the susceptibility of isolates to antibiotics as drug resistance constitutes a serious health concern in this locality (15). This information will be important for obtaining epidemiological insight and for determining appropriate, empirical antimicrobial therapy in both human and veterinary medicines.

\section{MATERIALS AND METHODS}

\section{Study design}

In total, 230 specimens were analyzed in the study. Fifty slaughtered cattle were sampled with 50 swabs each collected from the rectum, ileum, and contents of the gall bladder, giving 150 samples; 10 slaughtered pigs were sampled with three samples each collected from the same anatomical sites, such as the cattle for 30 samples; and 50 environmental samples were obtained from the abattoir drains. The samples were collected from different abattoirs, and sample sizes were selected based on convenience. More cattle were slaughtered than pigs in this and other abattoirs in Cameroon. The samples were collected during April-August 2006.

\section{Bacteriological analysis}

Specimens were collected and transported to the laboratory in selenite F medium following standard methods $(22,23)$. They were incubated for $24-48$ hours at $37^{\circ} \mathrm{C}$. The broth culture was aseptically streaked on Salmonella-Shigella agar (SS) and deoxycholate citrate agar (DCA) plates for the isolation of Salmonella. Plates were incubated at $37^{\circ} \mathrm{C}$ for 18-48 hours, after which they were examined for colonies typical of Salmonella. Suspect colonies were streaked on nutrient agar plates to obtain pure cultures which were subjected to oxidase testing, gram-staining, and motility testing. Gram-negative short-motile rods and non-motile rods with characteristic red slope/yellow butt reaction on TSI either with the production of $\mathrm{H}_{2} \mathrm{~S}$ or not were taken presumptively as Salmonella (22). They were further serotyped using agglutinating antisera (Murex Biotech Ltd., UK) based on the Kauffmann-White scheme as previously reported (24). Isolates were confirmed and classified into biotypes using the analytical profile index (API) 20E kit (Biomérieux SA, Marcy L' Etiole, France) following the instructions of the manufacturer.

\section{Antibiotic susceptibility testing}

The Kirby-Bauer disc-diffusion test, which conforms to the recommended standard of the Clinical and Laboratory Standards Institute (CLSI), formerly National Committee for Clinical Laboratory Standards (NCCLS), was used as previously described $(15,25)$. Briefly, a small inoculum of each pure bacterial isolate was emulsified in $3 \mathrm{~mL}$ of sterile normal saline in Bijou bottles, and the density was com- 
pared with a barium chloride standard ( 0.5 McFarland). A sterile cotton swab was dipped into the standardized suspension of bacterial cultures and used to evenly inoculate Mueller-Hinton plates (Biotec, England), and the plates were allowed to dry. Antibiotic discs with the following drug contents: gentamicin (GEN) $(10 \mu \mathrm{g})$; amikacin (AMK) $(10 \mu \mathrm{g})$; ciprofloxacin (CIP) $(5 \mu \mathrm{g})$; ofloxacin (OFX) $(10 \mu \mathrm{g})$; cefotaxime (CFT) $(30 \mu \mathrm{g})$; ceftazidine (CEF) $(30 \mu \mathrm{g})$; ampicillin (AMP) $(10 \mu \mathrm{g})$; amoxicillin (AMX) $(5 \mu \mathrm{g})$; tetracycline (TET) $(30 \mu \mathrm{g})$; doxycycline (DOX) $(10 \mu \mathrm{g})$; co-trimoxazole (SXT) $(25 \mu \mathrm{g})$; chloramphenicol (Chl) $(30 \mu \mathrm{g})$ (Antibiotic Becton, Dickson and Company, Sparks, USA; Le Point de Claix, France) were placed at least $15 \mathrm{~mm}$ apart and from the edge of the plates to prevent the overlapping of the inhibition zones. Plates were incubated at $37^{\circ} \mathrm{C}$ for 24 hours, and the diameters of zones of inhibition were compared with recorded diameters of the control organism E. coli ATCC 25922 to determine the susceptibility or resistance of isolates to various drugs. These antibiotics were chosen based on the prescription practices for Salmonella in this locality and from the literature (16).

\section{Statistical analysis}

The chi-square test was employed to compare the prevalence in the different anatomical sites and biotypes. The differences were considered significant at $\mathrm{p}<0.05$.

\section{RESULTS}

\section{Prevalence of S. Typhimurium}

Of the 230 specimens analyzed, 75 (32.6\%) were positive for $S$. Typhimurium. Samples from pigs and abattoir drains recorded a prevalence of $40 \%$ each while $28.7 \%$ was obtained from cattle (Table 1). The rectum had the highest isolation rate for cattle (41.9\%) and pigs (58.3\%) while the ileum had the least. There was, however, no significant difference $(p>0.05)$ in the distribution of the organism in the different anatomic sites of animals.

\section{Characterization of isolates}

All the isolates were Gram-negative, motile, short rods which were oxidase-negative with a typical red slope/yellow butt reaction in triple sugar iron (alkaline slope/acid butt) with the production of high amounts of hydrogen sulphide and gas. These isolates were taken presumptively as $S$. enterica. Confirmation was based on API 20E reactions and polyvalent antisera.

Biochemical characterization of the isolates resulted in five biotype patterns (I-V). Biotype I (30.7\%) and II (26.7\%) were the more prevalent while biotype IV $(9.3 \%)$ was the least. An interesting finding was that biotype IV was isolated from cattle and abattoir drains but not from pigs. The major difference between biotype IV and other biotypes was the use of inositol, in which only biotype IV was observed to use this sugar. However, biotype I, III, and V were more frequently isolated from pigs compared to the other biotypes. There was no significant ( $p>0.05$ ) difference in the distribution of biotypes. All biotypes from cattle also occurred in drains, indicating a probable link between biotypes from these sources.

\section{Antimicrobial susceptibility}

Susceptibility testing of isolates to 12 antimicrobial agents (Table 2) indicated that the quinolones (ciprofloxacin-98.6\%; ofloxacin-93.3\%) and the aminoglycosides (amikacin-90.6\%; gentamycin-84\%) were the most active drugs against the isolates. Tetracycline (100\%) and ampicillin (100\%), however, were the most resistant drugs. Marked resistance was also noted for amoxicillin (90.7\%), doxycycline (68\%), and co-trimoxazole (61.4\%). Multidrug resistance was a common phenomenon observed with $38(50.7 \%)$ of the 75 isolates. Fourteen antibiotic resistance patterns were obtained (Table $3)$. The predominant antibiotypes $A M X^{R} D O X^{R} C E-$ $\mathrm{F}^{\mathrm{R}}$ (amoxycillin, doxycycline, ceftriaxone) and

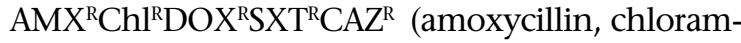
phenicol, doxycycline, co-trimoxazole, ceftazidine) were obtained from 13 (17.3\%) and 10 (13.3\%) of the isolates respectively. The least encountered patterns were $\mathrm{AMX}^{\mathrm{R}} \mathrm{Chl}^{\mathrm{R}}$ (amoxycillin, chloramphenicol), CAZ ${ }^{\mathrm{R}} \mathrm{CEF}^{\mathrm{R}} \mathrm{AMK}^{\mathrm{R}} \mathrm{AMX} \mathrm{X}^{\mathrm{R}} \mathrm{GEN}^{\mathrm{R}}$ (ceftazidine,

\begin{tabular}{|c|c|c|c|c|c|c|c|c|c|c|}
\hline \multirow{3}{*}{$\begin{array}{l}\text { Isolation of } \\
\text { pathogen }\end{array}$} & \multicolumn{10}{|c|}{ Sources of samples $(\mathrm{n}=230)$} \\
\hline & \multicolumn{3}{|c|}{ Cattle $(n=150)$} & \multicolumn{5}{|c|}{ Pigs $(\mathrm{n}=30)$} & \multicolumn{2}{|c|}{ Abattoir $(n=50)$} \\
\hline & Rectum & Ileum & $\begin{array}{c}\text { Gall } \\
\text { bladder }\end{array}$ & Total & Rectum & Ileum & $\begin{array}{c}\text { Gall } \\
\text { bladder }\end{array}$ & Total & Drain & Total \\
\hline No. positive & 18 & 11 & 14 & 43 & 7 & 2 & 3 & 12 & 20 & 75 \\
\hline$\%$ positive & 41.9 & 25.6 & 32.6 & 28.7 & 58 & 16.6 & 25.0 & 40.0 & 40.0 & 32.6 \\
\hline
\end{tabular}




\begin{tabular}{|lccccc|}
\hline \multicolumn{3}{|c}{ Table 2. Antibiotic susceptibility of Salmonella Typhimurium isolates } \\
\cline { 2 - 3 } Drug & \multicolumn{2}{c}{ Susceptible } & & \multicolumn{2}{c|}{ Resistant } \\
\cline { 2 - 3 } \cline { 5 - 5 } Ciprofloxacin & 74 & 98.6 & 1 & $\%$ \\
Ofloxacin & 70 & 93.3 & 5 & 13 \\
Amikacin & 68 & 90.6 & 7 & 6.7 \\
Gentamicin & 63 & 84.0 & 12 & 9.4 \\
Ceftazidine & 50 & 66.6 & 25 & 1.6 \\
Ceftriaxone & 37 & 49.3 & 38 & 33.4 \\
Tetracycline & 0 & 0.0 & 75 & 50.7 \\
Doxycycline & 24 & 32.0 & 51 & 100 \\
Ampicillin & 0 & 0.0 & 75 & 68 \\
Amoxycillin & 7 & 9.3 & 68 & 100 \\
Co-trimoxazole & 29 & 38.6 & 46 & 90.7 \\
Chloramphenicol & 38 & 50.6 & 37 & 61.4 \\
\hline
\end{tabular}

Table 3. Antibiotypes of Salmonella Typhimurium

\begin{tabular}{|c|c|c|c|}
\hline \multirow{2}{*}{ No. } & \multirow{2}{*}{ Antibiotype } & \multicolumn{2}{|c|}{ Strains } \\
\hline & & No. & $\%$ \\
\hline A1 & $\mathrm{AMX}^{\mathrm{R}} \mathrm{Chl}^{\mathrm{R}}$ & 1 & 1.3 \\
\hline $\mathrm{A} 2$ & $\operatorname{DOX}^{\mathrm{R}} \mathrm{Chl}^{\mathrm{R}}$ & 4 & 5.3 \\
\hline A3 & $\mathrm{AMX}^{\mathrm{R}} \mathrm{DOX}^{\mathrm{R}} \mathrm{CEF}^{\mathrm{R}}$ & 13 & 17.3 \\
\hline A4 & $\mathrm{AMX}^{\mathrm{R}} \mathrm{SXT}^{\mathrm{R}} \mathrm{DOX}^{\mathrm{R}}$ & 9 & 12.0 \\
\hline A5 & $\mathrm{AMX}^{\mathrm{R}} \mathrm{Chl}^{\mathrm{R}} \mathrm{SXT} \mathrm{T}^{\mathrm{R}}$ & 8 & 10.7 \\
\hline A6 & $\mathrm{DOX}^{\mathrm{R}} \mathrm{Chl}^{\mathrm{R}} \mathrm{CEF}^{\mathrm{R}}$ & 2 & 2.7 \\
\hline A7 & $\mathrm{AMX}^{\mathrm{R}} \mathrm{DOX}^{\mathrm{R}} \mathrm{Chl}^{\mathrm{R}} \mathrm{CEF}^{\mathrm{R}}$ & 8 & 10.7 \\
\hline A8 & OFX $^{\mathrm{R}} A M K^{\mathrm{R}} \mathrm{GEN}^{\mathrm{R}} S X T^{\mathrm{R}} A M X^{\mathrm{R}}$ & 5 & 6.7 \\
\hline A9 & $\mathrm{AMX}^{\mathrm{R}} \mathrm{Chl}^{\mathrm{R}} \mathrm{DOX}^{\mathrm{R}} \mathrm{SXT}^{\mathrm{R}} \mathrm{CAZ}^{\mathrm{R}}$ & 10 & 13.3 \\
\hline A10 & $A M X^{\mathrm{R}} \mathrm{CEF}^{\mathrm{R}} \mathrm{CAZ}^{\mathrm{R}} S X \mathrm{~T}^{\mathrm{R}} \mathrm{AMK}^{\mathrm{R}}$ & 5 & 6.7 \\
\hline A11 & $\mathrm{CAZ}^{\mathrm{R}} \mathrm{CEF}^{\mathrm{R}} A M K^{\mathrm{R}} A M X^{\mathrm{R}} \mathrm{GEN}^{\mathrm{R}}$ & 1 & 1.3 \\
\hline A12 & $\mathrm{CAZ}^{\mathrm{R}} \mathrm{CEF}^{\mathrm{R}} S \mathrm{XT}^{\mathrm{R}} \mathrm{DOX}^{\mathrm{R}} \mathrm{AMX}^{\mathrm{R}}$ & 7 & 9.3 \\
\hline A13 & $\mathrm{CIP}^{\mathrm{R}} \mathrm{CAZ}^{\mathrm{R}} \mathrm{CEF}^{\mathrm{R}} \mathrm{SX} \mathrm{T}^{\mathrm{R}} \mathrm{Ch} \mathrm{l}^{\mathrm{R}} \mathrm{GEN}^{\mathrm{R}}$ & 1 & 1.3 \\
\hline A14 & $\mathrm{CEF}^{\mathrm{R}} \mathrm{CAZ} \mathrm{Z}^{\mathrm{R}} \mathrm{SXT} \mathrm{T}^{\mathrm{R}} \mathrm{AMX^{ \textrm {R } }} \mathrm{AMK}^{\mathrm{R}} \mathrm{Chl}^{\mathrm{R}}$ & 1 & 1.3 \\
\hline Total & 14 & 75 & \\
\hline
\end{tabular}

ceftriaxone, amikacin, amoxycillin, gentamicin),

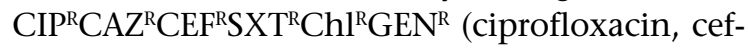
tazidine, ceftriazone, co-trimoxazole, chloramphenicol, gentamicin), $\mathrm{CEF}^{\mathrm{R}} \mathrm{CAZ}^{\mathrm{R}} \mathrm{SXT} \mathrm{T}^{\mathrm{R}} \mathrm{AMX} \mathrm{X}^{\mathrm{R}} \mathrm{AM}$ $\mathrm{K}^{\mathrm{R}} \mathrm{Chl}{ }^{\mathrm{R}}$ (ceftriaxone, ceftazidine, co-trimoxazole, amoxycillin, amikacin, chloramphenicol) as only one isolate each exhibited these patterns.

\section{DISCUSSION}

$S$. Typhimurium is a well-known zoonotic pathogen causing diarrhoea, pyrexia, and septicaemia in animals and humans. Non-typhoid Salmonella serovars remain a potential threat to human health, and beef cattle and broiler chickens are possible sources of these organisms in the environment (4). Although non-typhoidal salmonellosis in humans is usually a self-limiting disease confined to the intestinal tract, when infections spread beyond the intestine, or when immunocompromised persons are affected, it may have serious consequences requiring appropriate antimicrobial treatment. In animals, such symptoms can be lethal; so, prompt 
treatment with appropriate antimicrobial agents remains economically important. Hence, the surveillance of antimicrobial resistant strains is necessary for effective treatment and prediction of occurrence of resistant populations of prevailing biotypes. The public-health measures to reduce chances of infection, thus, take into consideration the presence of the organism in animals $(26,27)$. This study was, therefore, conducted to determine the biotypes and antibiogram of $S$. Typhimurium isolated from slaughtered food-animals (cattle and pigs) in Buea, Cameroon, where no such data exist.

$S$. Typhimurium was isolated from samples with a prevalence of $32.6 \%$. The distribution pattern was similar in both species of animals sampled where the organism was more frequently isolated from the rectum (41.9\% and 58.3\% from cattle and pigs respectively) (Table 1). The ileum of both animals had the least occurrence of the organism. We associate our findings to the fact that these animals shed the organism in faeces when placed under stress during slaughter (28). Thus, rectal swabbing offers an easy method of surveying the carrier rate of a specific herd. There was, however, no significant difference ( $>0.05$ ) in the distribution of the organism in the anatomical sites of animals. The high prevalence of Salmonella in these animals could result from consumption of contaminated feed $(29,30)$, or grazing plants that may have been contaminated through fertilization with untreated effluents or sludge.

Classical biotyping characterizes strains by creating profiles for a set of biochemical tests. Previous studies employed biotyping as a marker for assessing the widespread outbreak of $S$. Typhimurium-associated infections $(31,32)$. In our study, biotyping grouped isolates into five biotypes. Biotype I (30.6\%) and II $(26.7 \%)$ were the most frequently encountered. We observed a relationship between cattle and abattoir drains as all biotypes found in cattle were also obtained from drains. During slaughtering, the organisms are washed from cattle to open drains, and since the effluent is not properly disposed of, it may serve as a source for dissemination. Although we did not detect biotype IV in samples from porcine sources, we cannot declare the complete absence of this biotype from these sources as only a few swines were sampled due to a limited number of slaughtered swines in this locality and generally in abattoirs in Cameroon. In addition, although $S$. Typhimurium serotypes have been thought of as the prototypical broad-host-range serotypes, certain variants have been shown to have a narrow host range (6). We, therefore, speculate that the biotype
IV could have a narrow host range. All other biotypes were present in all samples analyzed.

Epidemiological surveillance of antimicrobial-resistant $S$. Typhimurium has become necessary for effective treatment and prediction of occurrence of resistant populations. Antibiogram of the isolates revealed marked susceptibility of isolates to quinolones-ciprofloxacin (98\%) and ofloxacin (93.3\%) (Table 2). Our results corroborate the findings of Esaki et al. (33) and Kawagoe et al. (20) who recently reported a marked susceptibility of $S$. Typhimurium to flouroquinolones that could be used in the treatment of infections caused by this organism. The high cost of these drugs in the study area discourages its over-use and may account for our observation of low antimicrobial resistance. Other active agents observed were the aminoglycosides-gentamicin (84\%) and amikacin (90.6\%). However, Kawagoe et al. recently reported resistance to these drugs in $S$. Typhimurium isolates from food-producing animals in Japan (20). We may not be certain as to these discrepancies but speculate that it may be related to differing prescription practices in these localities. It is noteworthy that all the isolates exhibited complete resistance (100\%) to tetracycline and ampicillin. Esaki et al. reported complete resistance to ampicillin, dihydrostreptomycin, oxytetracycline, and chloramphenicol in DT104 and 104B $S$. Typhimurium (33). A marked resistance was also observed to doxycycline (68\%) and amoxycillin $(90.7 \%)$. Their use may result in treatment failure. Although we reported a resistance of $49.4 \%$ to chloramphenicol, its veterinary use for food-animals has been prohibited in some countries.

Multidrug resistance was a common phenomenon in this study, being observed in 38 (50.7\%) of the 75 isolates. Fourteen distinct resistance patterns (antibiotypes) were observed. Pattern $\mathrm{AMX}^{\mathrm{R}} \mathrm{DOX} \mathrm{X}^{\mathrm{R}} \mathrm{CEF}{ }^{\mathrm{R}}$ was the most prevalent (17.3\%) while $\mathrm{CAZ}^{\mathrm{R}} \mathrm{CE}$ $\mathrm{F}^{\mathrm{R}} \mathrm{AMK}{ }^{\mathrm{R}} \mathrm{Chl}^{\mathrm{R}} \mathrm{GEN}^{\mathrm{R}}, \mathrm{CIP}^{\mathrm{R}} \mathrm{CAZ}^{\mathrm{R}} \mathrm{CEF}^{\mathrm{R}} \mathrm{SXT}^{\mathrm{R}} \mathrm{Chl}^{\mathrm{R}} \mathrm{GEN}^{\mathrm{R}}$, $\mathrm{CEF}^{\mathrm{R}} \mathrm{CAZ}^{\mathrm{R}} \mathrm{SXT}^{\mathrm{R}} \mathrm{OFX^{ \textrm {R } }} \mathrm{AMK}^{\mathrm{R}} \mathrm{Chl}^{\mathrm{R}}$, and $\mathrm{AMX}^{\mathrm{R}} \mathrm{Chl}^{\mathrm{R}}$ were the least common (1.3\%) (Table 3). The frequency of isolation of $S$. Typhimurium DT104 in food-animals worldwide has increased because of its spread and recent reports $(20,34)$ on changes in resistance phenotype, or phage-type in MDR $S$. Typhimurium underscores the need for continuous monitoring of susceptibility pattern of $S$. Typhimurium from food-animals. Our findings of high levels of multidrug-resistant Salmonella in slaughtered cattle and pigs and in the environment highlight the potential risk of $S$. Typhimurium DT 104, with multidrug resistance becoming established in Cam- 
eroon. Thus, routine investigations at a national level for drug-resistant $S$. Typhimurium in food-animals and prudent use of antimicrobials remain a high priority. Frequent surveillance to track changes in the susceptibility pattern of the organism in the study area is, therefore, advocated.

In conclusion, our results indicate that cattle and pigs could serve as reservoirs of $S$. Typhimurium in Buea, Cameroon and provide information on selection of antimicrobial therapy for infections due to $S$. Typhimurium in food-animals and for treatment of infections from these food sources. We advocate an urgent need for an organized Salmonella surveillance system that reports resistance patterns of $S$. enterica serotypes circulating in Cameroon.

\section{ACKNOWLEDGEMENTS}

The study was partly funded by the University of Buea, Cameroon. The authors are grateful for the collaboration received from the management of the Buea abattoir where samples were collected. Finally, the authors thank Mr. Monika Stephen for secretarial assistance.

\section{REFERENCES}

1. Yan SS, Pendrak ML, Abela-Ridder B, Punderson JW, Fedorka DP, Foley SL. An overview of Salmonella typing: public health perspectives. Clin Appl Immunol Rev 2004;4:189-204.

2. Hendriksen SWM, Orsel K, Wagenaar JA, Miko A, Van Duijkeren E. Animal-to-human transmission of Salmonella Typhimurium DT104A variant. Emer Infect Dis 2004;10:2225-7.

3. Smith-Palmer A, Stewart WC, Mather H, Greig A, Cowden JM, Reilly WJ. Epidemiology of Salmonella enterica serovars Enteritidis and Typhimurium in animals and people in Scotland between 1990 and 2001. $J$ Vet Rec 2003;153:517-20.

4. Abouzeed YM, Hariharan H, Poppe C, Kibenge FSB. Characterization of Salmonella isolates from beef cattle, broiler chickens and human source on Prince Edward Island. Comp Immunol Microbiol Infect Dis 2000;23:253-66.

5. Evans S, Davies R. Case control study of multiple-resistant Salmonella Typhimurium DT104 infection of cattle in Great Britain. Vet Rec 1996;139:557-8.

6. Rabsch W, Andrews HL, Kingsley RA, Prager R, Tschäpe H, Adams LG, Bäumler AJ. Salmonella enterica serotype Typhimurium and its host-adapted variants. Infect Immun 2002;70:2249-55.

7. Casadevall A, Pirofski L. Host-pathogen interaction: the attributes of virulence. J Infect Dis 2001;184:337-44.

8. Kranker S, Alban L, Boes J, Dahl J. Longitudinal study of Salmonella enterica serotype Typhimurium infection in three Danish farrow-to-finish swine herds. $J$ Clin Microbiol 2003;41:2282-8.

9. Murase T, Yamada M, Muto T, Matsushima A, Yamai S. Fecal excretion of Salmonella enterica serotype Typhimurium following a food-borne outbreak. J Clin Microbiol 2000;38:3495-7.

10. Torpdahl M, Sørensen G, Lindstedt B-A, Nielsen EM. Tandem repeat analysis for surveillance of human Salmonella Typhimurium infections. Emerg Infect Dis 2007;13:388-95.

11. Anderson ES, Ward LR, Saxe MJ, de Sa JD. Bacteriophage-typing designations of Salmonella typhimurium. J Hyg (London) 1977;78:297-300.

12. Corbett-Feeney G, Riain UN. The use of pulsedfield gel electrophoresis for subdivision of Salmonella typhimurium in an outbreak situation. J Infect 1998;36:175-7.

13. Threlfall EJ, Rowe B, Ferguson JL, Ward LR. Characterization of plasmids conferring resistance to gentamicin and apramycin in strains of Salmonella typhimurium phage type 204c isolated in Britain. J Hyg (London) 1986;97:419-26.

14. Zhou G, Ru W, Liao Y. The application of Salmonella typhimurium biotyping method to the epidemiological surveys and surveillance. Zhonghua Liu Xing Bing Xue Za Zhi 1998;19:221-3.

15. Ndip RN, Dilonga HM, Ndip LM, Akoachere JFK, Nkuo-Akenji T. Pseudomonas aeruginosa isolates recovered from clinical and environmental samples in Buea, Cameroon: current status on biotyping and antibiogram. Trop Med Int Health 2005;10:74-81.

16. Besser TE, Goldoft M, Pritchett LC, Khakhria R, Hancock DD, Rice DH et al. Multiresistant Salmonella Typhimurium DT104 infections of humans and domestic animals in Pacific Northwest of the United States. Epidemiol Infect 2000;124:193-200.

17. Butaye P, Michael GB, Schwarz S, Barrett TJ, Brisabois A, White DG. The clonal spread of multidrug-resistant non-typhi Salmonella serotypes. Microbes Infect 2006;8:1891-7.

18. Arlet G, Barrett TJ, Butaye P, Cloeckaert A, Mulvey MR, White DG. Salmonella resistant to extendedspectrum cephalosporins: prevalence and epidemiology. Microbes Infect 2006;8:1945-54.

19. Weinberger M, Keller N. Recent trends in the epidemiology of non-typhoid Salmonella and antimicrobial resistance: the Israeli experience and worldwide review. Curr Opin Infect Dis 2005;18:513-21.

20. Kawagoe K, Mine H, Asai T, Kojima A, Ishihara K, Harada $\mathrm{K}$ et al. Changes in mult-drug resistance pattern in Salmonella enterica subspecies enterica serovar 
typhimurium isolates from food-producing animals in Japan. J Vet Med Sci 2007;69:1211-3.

21. Nkuo-Akenji TK, Ntemgwa ML, Ndip RN. Asymptomatic salmonellosis and drug susceptibility in Buea District, Cameroon. Cent Afr J Med 2001;47:254-7.

22. Cheesbrough M. Microbiological tests. Chapter 7. In: Cheesbrough $\mathrm{M}$, editor. District laboratory practice in tropical countries, pt 2. $2 \mathrm{~d}$ ed. Cambridge: Cambridge University Press, 2006:9-267.

23. Winn WC, Jr., Allen S, Janda W, Koneman E, Procop G, Schreckenberger P et al. The Enterobacteriaceae. In: Koneman's Colour atlas and textbook of diagnostic microbiology. 6th ed. Philadelphia: Lippincott Williams and Wilkins, 2006:211-303.

24. Santos FB, Dsouza DH, Jaykus L, Ferket PR, Sheldon BW. Genotypes, serotypes, and antibiotic resistance profiles of Salmonella isolated from commercial North Carolina turkey farms. J Food Prot 2007;70:1328-33.

25. Bauer AW, Kirby WM, Sherris JC, Turck M. Antibiotic susceptibility testing by a standardized single disk method. Am J Clin Pathol 1966;45:493-6.

26. Skov MN, Andersen JS, Aabo S, Ethelberg S, Aarestrup FM, Sørensen AH et al. Antimicrobial drug resistance of Salmonella isolates from meat and humans, Denmark. Emerg Infect Dis 2007;13:638-41.

27. Woldemarian E, Molla B, Alemayehu D, Muckle A. Prevalence and distribution of Salmonella in apparently healthy slaughtered sheep and goat in Debre Zeit, Ethiopia. Small Rumin Res 2005;58:19-24.
28. Hume ME, Edrington, TS, Looper ML, Callaway TR, Genovese KJ, Nisbet DJ. Salmonella genotype diversity in nonlactating and lactating diary cows. J Food Protect 2004;67:2280-3.

29. Kidd RS, Rossignol AM, Gamroth MJ. Salmonella and other Enterobacteriaceae in diary-cow feed ingredients: antimicrobial resistance in western Oregon. J Environ Health 2002;64:9-16.

30. Davies RH, Dalziel R, Gibbens JC, Wilesmith JW, Ryan JM, Evans SJ et al. National survey for Salmonella in pigs, cattle and sheep at slaughter in Great Britain (1999-2000). J Appl Microbiol 2004;96:750-60.

31. Ishiguro N, Sato G. Biotyping of Salmonella typhimurium strains isolated from animals and birds in northern Japan. Am J Vet Res 1981;42:896-7.

32. Allos G, Vieu, JF, Najat K, Ghassan I. Biotypes of Salmonella typhimurium in Iraq. Bull Soc Pathol Exot Filiales 1984;77:284-7.

33. Esaki H, Morioka A, Ishihara K, Kojima A, Shiroki S, Tamura Y et al. Antimicrobial susceptibility of Salmonella isolated from cattle, swine and poultry (2001-2002): report from the Japanese Veterinary Antimicrobial Resistance Monitoring Programme. J Antimicrob Chemother 2004;53:266-70.

34. Wedel SD, Bender JB, Leano FT, Boxrud DJ, Hedberg C, Smith KE. Antimicrobial-drug susceptibility of human and animal Salmonella typhimurium, Minnesota, 1997-2003. Emerg Infect Dis 2005;11:1899-906. 